\title{
Letter to the Editor on "Prediction of Knee Kinematics at Time of Noncontact Anterior Cruciate Ligament Injuries Based on Bone Bruises"
}

\author{
Alberto Grassi, ${ }^{1}$ Piero Agostinone, ${ }^{1}$ Stefano Di Paolo ${ }^{0},{ }^{2}$ \\ and SteFAnO ZAFFAGNini ${ }^{1,2}$ \\ ${ }^{1}$ Clinica Ortopedica e Traumatologica II, IRCCS Istituto Ortopedico Rizzoli, Bologna, Italy; and ${ }^{2}$ Dipartimento di Scienze \\ Biomediche e Neuromotorie DIBINEM, Università di Bologna, Via Giulio Cesare Pupilli, 1, 40136 Bologna, BO, Italy
}

(Received 22 June 2020; accepted 15 July 2020; published online 20 July 2020)

Associate Editor Jane Grande-Allen oversaw the review of this article.

\begin{abstract}
The aim of the present Letter was to comment on the paper "Prediction of Knee Kinematics at Time of Noncontact Anterior Cruciate Ligament Injuries Based on Bone Bruises" from Shi et al. (Ann Biomed Eng, 2020, h ttps://doi.org/10.1007/s10439-020-02523-y). Though the authors provided an extremely interesting paper on a debated topic in Sport Medicine, with a strong methodology and consistent results, caution should be used when drawing conclusions on Anterior Cruciate Ligament injury mechanism through the interpretation of such data.
\end{abstract}

Keywords-Bone bruises, Anterior Cruciate Ligament, Injury Mechanism, Knee Kinematics.

We read with enormous interest the paper "Prediction of Knee Kinematics at Time of Noncontact Anterior Cruciate Ligament Injuries Based on Bone Bruises" from Shi et al. ${ }^{15}$ First of all, we congratulate with the authors for employing cutting edge technologies to shed light on an extremely debated topic in Sports Medicine, which is the mechanism of Anterior Cruciate Ligament (ACL) rupture. The authors created a 3D MRI-based model of the tibia and femur, which was positioned within the 3 spatial planes by matching the tibial and femoral bone bruises areas in the lateral compartment, in order to recreate the tibio-fermoral position "near the time of ACL injury". ${ }^{15}$ Bone bruises are indeed believed to "represent a footprint of the impact at time of ACL

Address correspondence to Stefano Di Paolo, Dipartimento di Scienze Biomediche e Neuromotorie DIBINEM, Università di Bologna, Via Giulio Cesare Pupilli, 1, 40136 Bologna, BO, Italy. Electronic mail: stefano.dipaolo@ior.it injury" 15 and their study has been considered useful to gain insight into the mechanism of ACL injury., 10,14,16

The authors found important and interesting findings: according to their model of lateral bone bruises matching, tibio-femoral impact occurs at an average flexion near $35^{\circ}$ (as extrapolated from their Fig. 1), anterior tibial translation of $34.3 \mathrm{~mm}$, external rotation near $10^{\circ}$ and knee abduction (valgus) near $10^{\circ}$. This position, which significantly differed from the "resting" MRI position, is extremely consistent with the findings reported in a study with a similar methodology presented by our group at the Italian Congress of Orthopaedics and Traumatology (SIOT) in $2019^{6}$ and scheduled as a free paper presentation at the 2020 European Society of Sports traumatology, Knee and Arthroscopy (ESSKA) Congress, which was not however presented due to the COVID-19 pandemic. According to our model, which included patients with both medial and lateral bone bruises (to increase matching accuracy) and that used the in vivo weightbearing condition (acquired through a Dynamic Roentgen-Stereophotogrammetric Analysis $^{1-4,13}$ ) as reference baseline position, we found that bone bruises occur with a knee flexion above $30^{\circ}$, and with an average anterior tibial translation of $28.4 \mathrm{~mm}$, external rotation of $13.7^{\circ}$ and knee valgus of $10.6^{\circ}$.

Our values are extremely consistent with those of Shi et al., ${ }^{15}$ thus suggesting a similar behavior of the ACL injury mechanism either in the case of bone bruises involving the single lateral compartment or involving the medial and lateral compartments simultaneously. Thus, we strongly support their method and their results. 


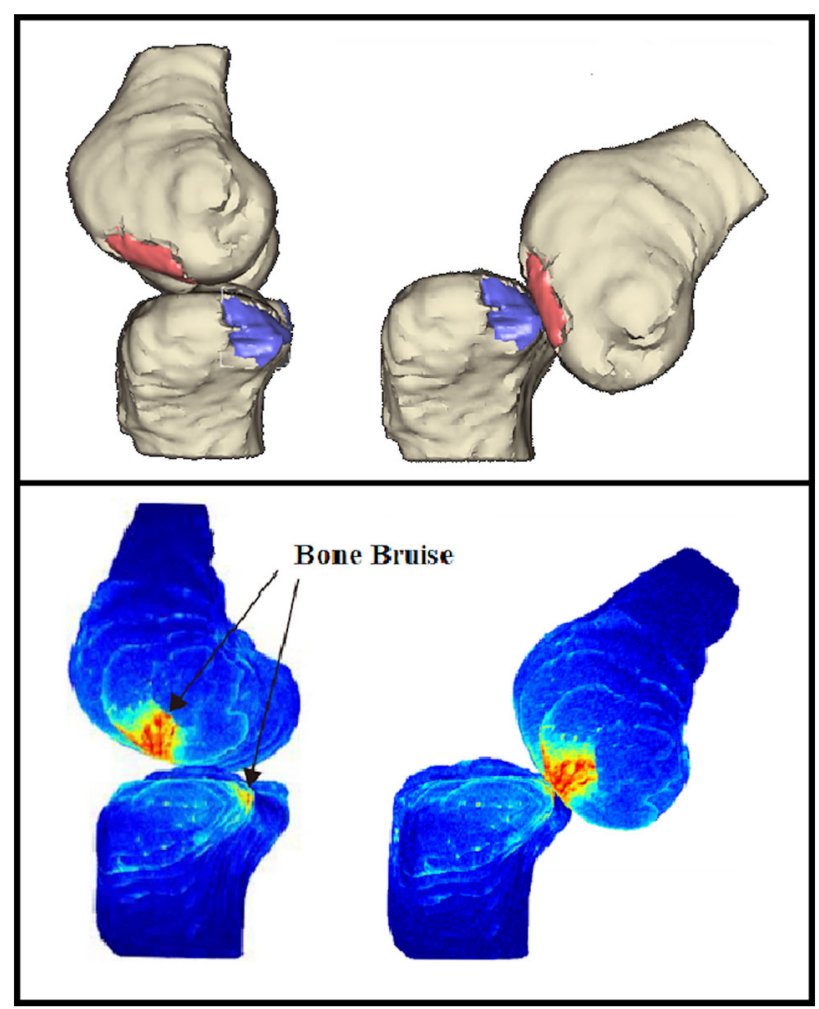

FIGURE 1. Knee position obtained in our research study ${ }^{6}$ through MRI-based model-matching of the bone bruises (red for femur, blue for tibia) on medial and lateral compartments (top); knee position obtained in the study of Shi et al. ${ }^{15}$ (bottom).

However, extreme caution should be used when interpreting such results. The authors indeed concluded that "excessive external tibial rotation when combined with knee flexion and extreme valgus may be the predisposing biomechanical factor to the ACL injury" and that these could be considered as "high-risk movement patterns for ACL injury", thus suggesting that "ACL injury prevention programs should focus more on constraining knee valgus and external rotation".

Drawing such conclusions from this biomechanical evidence could be misleading without examining indepth the current knowledge of ACL injury mechanism. Indeed, one of the most reliable models, which more closely resembles the real in vivo condition, is the model described by Koga et al. ${ }^{12}$ They have been the first and the only to investigate the ACL injury mechanism by applying a Mode-Based Image Matching (MBIM), which allowed them to analyze the tibiofemoral kinematics during in vivo noncontact ACL injuries in athletes by matching the 3D skeletal models with bi-dimensional images (obtained from video footages) according to anatomical landmarks. The authors were thus able to identify 3 distinct phases of the injury mechanism based on rotational and trans- lational motions: (1) an initial phase of lateral compression when an axial and knee valgus loads are applied on the early-flexed knee; (2) a second phase when anterior tibial translation and internal rotation occurs, resulting in ACL rupture; (3) a final phase when anterior displacement and flexion increase, and external rotation occurs.

Examining the data provided by Koga et al., ${ }^{11,12}$ the plateau of anterior tibial translation (above $20 \mathrm{~mm}$ ) seems to occur approximately between 50 and $100 \mathrm{~ms}$ after initial ground contact, thus after ligament rupture, with knee flexed above $30^{\circ}$ and when tibial rotation is reversing from internal to external rotation. This translational and rotational pattern described in the late phase of injury mechanism seems consistent with the pattern reported by matching bone bruises.

Thus, it is our opinion that bone bruises occur AFTER ACL rupture, when the tibial and femoral motion is guided by the abnormal kinematics due to the ligamentous injury and the traumatic inertial energies, exposing to contact articular surfaces that would not be normally overlapped during physiological motion. In our opinion, with the current knowledge, it is thus not appropriate to formulate recommendations on ACL injury prevention based on models obtained from bone bruises matching. Further in vivo studies are needed to accurately determine the exact moment of bone bruises occurrence, ideally matching 3D-MRI knee models with in vivo ACL injury video captures in media exposed athletes. ${ }^{5,7,8} \mathrm{We}$ agree that such task would be extremely complex, but hopefully in the near future technological development will allow us to deepen our knowledge in this fascinating and barely explored topic.

\section{CONFLICT OF INTEREST}

No benefits in any form have been or will be received from a commercial party related directly or indirectly to the subject of this manuscript.

\section{REFERENCES}

${ }^{1}$ Agostinone, P., S. Di Paolo, A. Grassi, E. Pinelli, M. Bontempi, L. Bragonzoni, and S. Zaffagnini. ACL deficiency influences medio-lateral tibial alignment and knee varus-valgus during in vivo activities. Knee Surg. Sports Traumatol. Arthrosc 2020. https://doi.org/10.1007/s00167020-05979-6.

${ }^{2}$ Alesi, D., G. M. Marcheggiani Muccioli, T. R. di Sarsina, M. Bontempi, N. Pizza, R. Zinno, S. Di Paolo, S. Zaffagnini, and L. Bragonzoni. In vivo femorotibial kinematics of medial-stabilized total knee arthroplasty 
correlates to post-operative clinical outcomes. Knee Surg. Sports Traumatol. Arthrosc. 2020. https://doi.org/10.1007/ s00167-020-05975-w.

${ }^{3}$ Bonanzinga, T., C. Signorelli, M. Bontempi, A. Russo, S. Zaffagnini, M. Marcacci, and L. Bragonzoni. Evaluation of RSA set-up from a clinical biplane fluoroscopy system for 3D joint kinematic analysis. Joints 4:121-125, 2016.

${ }^{4}$ Bontempi, M., U. Cardinale, L. Bragonzoni, G. M. M. Muccioli, D. Alesi, B. di Matteo, M. Marcacci, and S. Zaffagnini. A computer simulation protocol to assess the accuracy of a Radio Stereometric Analysis (RSA) image processor according to the ISO-5725. ArXiv200603913 Phys., 2020. http://arxiv.org/abs/2006.03913.

${ }^{5}$ Della Villa, F., M. Buckthorpe, A. Grassi, A. Nabiuzzi, F. Tosarelli, S. Zaffagnini, and S. Della Villa. Systematic video analysis of ACL injuries in professional male football (soccer): injury mechanisms, situational patterns and biomechanics study on 134 consecutive cases. $\mathrm{Br}$. J. Sports Med. 2020. https://doi.org/10.1136/bjsports-2019-101247.

${ }^{6}$ Grassi, A., P. Agostinone, L. Macchiarola, G. A. Lucidi, S. Di Paolo, M. Bontempi, L. Bragonzoni, and S. Zaffagnini. Modello tridimensionale dei bone bruises associati alla lesione del Legamento Crociato Anteriore, 2019.

${ }^{7}$ Grassi, A., S. P. Smiley, T. R. di Sarsina, C. Signorelli, G. M. Marcheggiani Muccioli, A. Bondi, M. Romagnoli, A. Agostini, and S. Zaffagnini. Mechanisms and situations of anterior cruciate ligament injuries in professional male soccer players: a youtube-based video Analysis. Eur. J. Orthop. Surg. Traumatol. Orthop. Traumatol. 27:967-981, 2017.

${ }^{8}$ Grassi, A., F. Tosarelli, P. Agostinone, L. Macchiarola, S. Zaffagnini, and F. Della Villa. Rapid Backward Tibial Reduction Following Noncontact Anterior Cruciate Ligament Rupture: Mechanism Description from a VideoAnalysis. Sports Health (in press), 2020.

${ }^{9}$ Hewett, T. E., G. D. Myer, K. R. Ford, R. S. Heidt, A. J. Colosimo, S. G. McLean, A. J. van den Bogert, M. V. Paterno, and P. Succop. Biomechanical measures of neuromuscular control and valgus loading of the knee predict anterior cruciate ligament injury risk in female athletes: a prospective study. Am. J. Sports Med. 33:492-501, 2005.

${ }^{10}$ Kim, S. Y., C. E. Spritzer, G. M. Utturkar, A. P. Toth, W. E. Garrett, and L. E. DeFrate. Knee kinematics during noncontact anterior cruciate ligament injury as determined from Bone Bruise location. Am. J. Sports Med. 43:25152521, 2015.

${ }^{11}$ Koga, H., R. Bahr, G. Myklebust, L. Engebretsen, T. Grund, and T. Krosshaug. Estimating anterior tibial translation from model-based image-matching of a noncontact anterior cruciate ligament injury in professional football: a case report. Clin. J. Sport Med. Off. J. Can. Acad. Sport Med. 21:271-274, 2011.

${ }^{12}$ Koga, H., A. Nakamae, Y. Shima, J. Iwasa, G. Myklebust, L. Engebretsen, R. Bahr, and T. Krosshaug. Mechanisms for noncontact anterior cruciate ligament injuries: knee joint kinematics in 10 injury situations from female team handball and basketball. Am. J. Sports Med. 38:2218-2225, 2010.

${ }^{13}$ Marcheggiani Muccioli, G. M., N. Pizza, S. Di Paolo, R. Zinno, D. Alesi, T. R. Di Sarsina, M. Bontempi, S. Zaffagnini, and L. Bragonzoni. Multi-radius posterior-stabilized mobile-bearing total knee arthroplasty partially produces in vivo medial pivot during activity of daily living and high demanding motor task. Knee Surg. Sports Traumatol. Arthrosc. 2020. https://doi.org/10.1007/s00167-02005846-4.

${ }^{14}$ Owusu-Akyaw, K. A., S. Y. Kim, C. E. Spritzer, A. T. Collins, Z. A. Englander, G. M. Utturkar, W. E. Garrett, and L. E. DeFrate. Determination of the position of the knee at the time of an anterior cruciate ligament rupture for male versus female patients by an analysis of Bone Bruises. Am. J. Sports Med. 46:1559-1565, 2018.

${ }^{15}$ Shi, H., L. Ding, S. Ren, Y. Jiang, H. Zhang, X. Hu, H. Huang, and Y. Ao. Prediction of knee kinematics at the time of noncontact anterior cruciate ligament injuries based on the Bone Bruises. Ann. Biomed. Eng. 2020. https://doi. org/10.1007/s10439-020-02523-y.

${ }^{16}$ Zhang, L., J. D. Hacke, W. E. Garrett, H. Liu, and B. Yu. Bone Bruises associated with anterior cruciate ligament injury as indicators of injury mechanism: a systematic review. Sports Med. Auckl. N.Z. 49:453-462, 2019.

Publisher's Note Springer Nature remains neutral with regard to jurisdictional claims in published maps and institutional affiliations. 